\title{
Correction to: Modified Lefort partial colpocleisis
}

\section{Hongtao Lv ${ }^{1} \cdot$ Fengnian Rong ${ }^{1}$}

Published online: 17 February 2021

(C) The International Urogynecological Association 2021

\section{Erratum to: International Urogynecology Journal \\ https://doi.org/10.1007/s00192-020-04545-5}

The original version of this article unfortunately contained a mistake. The funding \# found in the Acknowledgements section was incorrectly given as SQ20180052. The correct funding \# is 2018WS259. Therefore the first paragraph of the Acknowledgements should read:

Acknowledgements This work was supported by Shandong Provincial Medical and Health Science and Technology Development Plan (2018WS259).

The original article has been corrected.

Publisher's note Springer Nature remains neutral with regard to jurisdictional claims in published maps and institutional affiliations.

The online version of the original article can be found at https://doi.org/ 10.1007/s00192-020-04545-5

Fengnian Rong

fnrong@163.com

1 Department of Gynecology and Obstetrics, The First Affiliated Hospital of Shandong First Medical University \& Shandong Provincial Qianfoshan Hospital, Jinan 250014, Shandong, China 